Maria Engel de Oliveira

\title{
ORKUT: O Impacto da Realidade da Infidelidade Virtual
}

\author{
DISSERTAÇÃO DE MESTRADO
}

\author{
DEPARTAMENTO DE PSICOLOGIA \\ Programa de Pós-Graduação em Psicologia
}




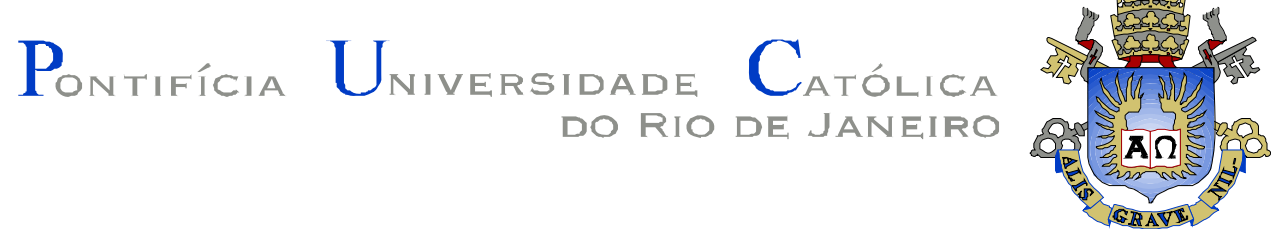

Maria Engel de Oliveira

ORKUT: O Impacto da Realidade da Infidelidade
Virtual

Dissertação de Mestrado

Dissertação apresentada ao Programa de Pós-graduação de Psicologia como requisito parcial para obtenção do título de Mestre em Psicologia.

Orientador: Prof. Bernardo Jablonski

Rio de Janeiro

Fevereiro de 2007 
Maria Engel de Oliveira

\section{ORKUT: O Impacto da Realidade da Infidelidade Virtual}

Dissertação apresentada como requisito parcial para obtenção do grau de Mestre pelo Programa de PósGraduação em Psicologia Clínica do Departamento de Psicologia do Centro de Teologia e Ciências Humanas da PUC-Rio. Aprovada pela Comissão Examinadora abaixo assinada.

Prof. Bernardo Jablonski

Orientador

Departamento de Psicologia - PUC-Rio

Profa. Terezinha Féres-Carneiro

Departamento de Psicologia - PUC-Rio

Profa. Mirian Goldenberg

Instituto de Filosofia e Ciências Sociais - UFRJ

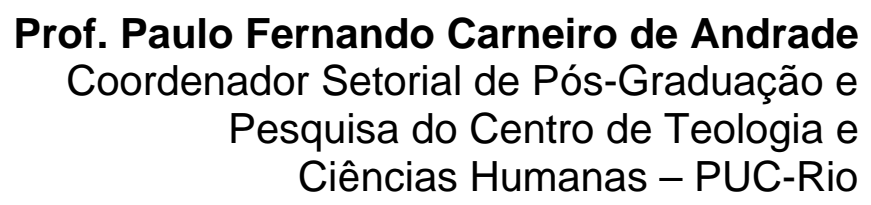

Rio de Janeiro, 26/02/07 
Todos os direitos reservados. É proibida a reprodução total ou parcial do trabalho sem autorização da universidade, da autora e do orientador.

\section{Maria Engel de Oliveira}

Graduou-se em Psicologia pela PUC-Rio em 2002. Cursou Especialização em Assistência a Usuários de Álcool e Drogas pelo Instituto de Psiquiatria da UFRJ em 2005. Realiza atendimentos clínicos tanto em consultório particular como também em uma clínica social.

Ficha Catalográfica

Oliveira, Maria Engel de

ORKUT: o impacto da realidade da infidelidade virtual / Maria Engel de Oliveira ; orientador: Bernardo Jablonski. - 2007.

103 f. : il. ; $30 \mathrm{~cm}$

Dissertação (Mestrado em Psicologia)-Pontifícia Universidade Católica do Rio de Janeiro, Rio de Janeiro, 2007.

Inclui bibliografia

1. Psicologia - Teses. 2. Infidelidade. 3. Infidelidade online. 4. Traição. 5. Adultério. 6. Internet. 7. Relacionamentos virtuais. 8. Orkut. I. Jablonski, Bernardo. II. Pontifícia Universidade Católica do Rio de Janeiro. Departamento de Psicologia. III. Título.

CDD: 150 


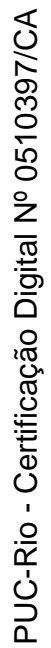

Para minha mãe, pelo apoio e carinho de sempre. 


\section{Agradecimentos}

Ao meu orientador Bernardo Jablonski, obrigada por ter "aparecido" no momento certo do curso de Mestrado, pelas tantas indicações de leitura e estudo, e por tantas palavras de apoio e incentivo ao longo do meu árduo percurso de elaboração desta dissertação.

Aos meus amigos "reais" e "virtuais" por terem me apoiado em momentos muito difíceis do curso de Mestrado.

Aos amigos que conquistei durante o curso de Mestrado, especialmente Maria Cláudia, Luciana e Reivani, que estiveram presentes, cada uma do seu jeito, em diferentes situações inusitadas e complicadas, me ajudando no que foi possível.

À Prof ${ }^{\mathrm{a}}$ Ana Maria Rudge, coordenadora de Pós-graduação de Psicologia, por ter me guiado e aberto novos caminhos em um momento crucial do curso de Mestrado, com muita paciência e atenção.

À Maria Tereza, pela escuta carinhosa e humana, obrigada pelo colo!

À Maria de Fátima Amin, minha supervisora clínica, obrigada pelas palavras de incentivo e de não desistência dos meus ideais de vida!

À minha mãe, minha melhor amiga, por estar sempre conseguindo me dar forças incríveis para que eu siga minha vida e minha profissão!

A meu pai, eterna inspiração e luz na minha vida, para todo e sempre!

A Leonardo Garrido Visentin, pela ajuda no tocante ao tema desta dissertação, pela compreensão em todos os momentos em que precisei 
ficar mais recolhida durante a elaboração deste trabalho e por ter me incentivado a seguir sempre em frente e de cabeça erguida!

A todos os sujeitos “virtuais” que aceitaram participar da pesquisa de campo deste trabalho, pois sem eles esta dissertação não seria a mesma.

A todos os funcionários do Departamento de Psicologia, em especial à Marcelina de Andrade, secretária da Pós-graduação, por palavras incentivadoras ao telefone.

À VRAc - PUC-Rio, e ao CNPq pelo apoio financeiro, sem o qual este trabalho não seria possível.

Ao meu lado espiritual, o qual procurei trabalhar e equilibrar durante o meu percurso no curso de Mestrado, que foi cheio de obstáculos, dificuldades e frustrações, mas também foi feito de pessoas e surpresas agradáveis e, finalmente, de conquistas. 


\section{Resumo}

Oliveira, Maria Engel de. Orkut: O Impacto da Realidade da Infidelidade Virtual. Rio de Janeiro, 2007. 103 p. Dissertação de Mestrado - Departamento de Psicologia, Pontifícia Universidade Católica do Rio de Janeiro.

Traição, infidelidade e adultério são temas que geram até hoje diversas reações e opiniões nas pessoas. Em diferentes momentos históricos e culturais podemos dizer que o ser humano vivenciou as três situações de formas diversas. Por ora foram socialmente aceitos, e em outros momentos, punidos e vistos como pecado. Mas existe um consenso com relação à reação frente à descoberta de uma traição, que é o fato de ser geradora de muito sofrimento, decepção e de um sentimento de condenação por parte de quem a descobre. Com o advento da Internet, surgem os relacionamentos virtuais e, por conseguinte, novas facetas começam a ser reveladas com relação à infidelidade. A comunidade virtual Orkut serviu de pano de fundo para este trabalho, pois lá existe uma liberdade de acesso por parte dos seus membros às informações pessoais, fotos e mensagens que são trocadas. A possibilidade de visualização de conteúdos que possam denunciar a infidelidade ou a traição por parte de alguém é muito grande. Desta maneira, o presente trabalho teve como objetivo principal investigar os principais sentimentos e opiniões dos usuários do Orkut a respeito da infidelidade online. Foi realizada uma pesquisa qualitativa com dez sujeitos, usuários do Orkut, através de entrevistas online. Quinze depoimentos da comunidade "Eu descobri pelo Orkut” também foram analisados. Os resultados revelaram principalmente que a troca de mensagens mais ardentes, carinhosas ou "ilícitas” pelo Orkut é considerada como traição pelos sujeitos, assim como a visualização de fotos de outros homens e mulheres.

\section{Palavras-chave}

Infidelidade, traição, adultério, Internet, relacionamentos virtuais, Orkut, infidelidade online. 


\section{Abstract}

Oliveira, Maria Engel de. Orkut: The Impact of Reality of the Virtual Infidelity. Rio de Janeiro, 2007. 103 p. MSc. Dissertation - Departamento de Psicologia, Pontifícia Universidade Católica do Rio de Janeiro.

Betrayal, infidelity and adultery are subjects that cause several reactions and opinions on people, until today. In different historical and cultural moments, we can say that the human being lived those situations differently. For the time being, they were socially accepted, and in other moments, punished and seen as sins. But there is a consensus in relation to the reaction of people facing the discovery of a betrayal, which causes a lot of pain, deception and a feeling of censure from those who find it out. With the happening of Internet, virtual relationships emerge, therefore, new strategies start being revealed in relation of infidelity. The virtual community Orkut, performed as a background for this project, because there is a freedom of access, on the behalf of the users, to personal information, pictures and messages which are swapped. The possibility to visualize the contents that may denounce the infidelity or betrayal of someone is huge. Thereby, this project had as its main goal, to investigate the main feelings and opinions from users of Orkut, about infidelity online. A quality research was performed with ten users through interviews online. Fifteen testimonials from the community "Eu descobri pelo Orkut” were also analyzed. The results mainly revealed that the swap of spicy, tender or "illicit" messages by Orkut, are considered betrayal, such as to visualize pictures from other men or women.

\section{Key-words}

Infidelity, betrayal, adultery, Internet, virtual relationships, Orkut, infidelity online. 


\section{Sumário}

1. Introdução

2. A Traição, A Infidelidade, $O$ Adultério e Os Relacionamentos $\begin{array}{ll}\text { Extraconjugais ao longo do tempo } & 14\end{array}$

2.1. O Adultério - um ato comum ou incomum? Prazer ou dor? 16

2.2. O surgimento do padrão de dupla moral 23

2.3. Os castigos contra os praticantes do adultério 25

2.4. As pesquisas sobre o adultério, a infidelidade e a traição 27

2.4.1. O Trabalho de A. Lawson 32

2.4.2. Tipos de Adultério 33

2.5. Razões para a infidelidade e para o adultério 35

3. O Surgimento da Internet 39

3.1. Os relacionamentos virtuais: quais são suas características e quem são as pessoas que se engajam neles? 40

3.2. As Comunidades Virtuais 43

3.2.1. O Orkut 44

3.3. Relacionamentos Virtuais X Relacionamentos Reais 48

3.4. A Infidelidade Online: Por que, Onde e Como? 51

3.4.1. De que forma a infidelidade online é sentida pelo parceiro que a descobre? 54

3.4.2. Infidelidade online: Uma realidade freqüente 56

4. A Pesquisa de Campo $\quad 59$

4.1. Objetivo $\quad 59$

4.2. Metodologia 60

4.2.1. Os Sujeitos da Pesquisa - A Busca 60

4.2.2. A Preservação do Anonimato dos Sujeitos 63 
4.4. As entrevistas online X presenciais 66

$\begin{array}{ll}\text { 4.5. A Análise dos Dados } & 67\end{array}$

5. A Apresentação dos Resultados da Pesquisa de Campo 69

5.1. O Perfil dos Sujeitos Entrevistados 69

5.2. Razões para estarem no Orkut 70

5.3. Por que fazer parte de uma comunidade cujo tema é a traição? 72

5.4. E o que é a traição de fato e o que significa infidelidade? 73

5.5. E na Internet, como ficam a traição e a infidelidade? 74

5.6. Conhecimento dos Sujeitos a respeito de casos de traição 75

5.7. Quais seriam as reações dos sujeitos perante a traição? 76

5.8. Diferenças entre a infidelidade no mundo real e a virtual 78

5.9 O que descobriram os membros do Orkut? 80

5.9.1. Uma breve análise dos depoimentos 82

6. Discussão dos Resultados das Entrevistas 85

$\begin{array}{ll}\text { 7. Considerações Finais } & 90\end{array}$

8. Referências Bibliográficas 94

$\begin{array}{lr}\text { 9. Anexo } 1 & 100\end{array}$

$\begin{array}{lr}\text { 10. Anexo } 2 & 103\end{array}$ 
Os computadores mudaram não só o modo como trabalhamos como também a forma como amamos. Apaixonar-se ou não, flertar, trair e até mesmo fazer sexo online, tudo isso se tornou parte da mais moderna maneira como vivemos e amamos.

Aaron Ben-Ze’ev, Love Online: Emotions On The Internet. 